\title{
The Wisdom of the Many and Fichte’s “We”
}

\author{
Sander Wilkens \\ Technische Universität Berlin
}

\begin{abstract}
In order to consider the Wisdom of the Many, one has to reconsider Aristotle's statement about the source of a nation-state concerning political "gregarism"-how it is called today, and why this belongs to the essentials of political constitution. Beforehand, this concept should not provide an instance of theoretical indulgence for emotional concepts or alike. Then, this statement will have to be confronted with the core argument of the Wisdom of the Many, together with the interpretation of Waldron. It will be interpreted as the counterpart of gregarism: When several people find together a solution, which eventually overrules that of the (few) expert(s), they rely upon a common focus or an instance of polar consciousness. This includes the final question if the shared consciousness — or the polarity condition—is not able to also dominate and manifest within a group of experts, of those sufficiently erudite. As a token of possible evidence, the answer is given with Fichte, his lecture of the Science of Knowledge of 1804 by reason of the succinct reliance upon the plural "We."
\end{abstract}

Keywords: gregarism, polarity, focal consciousness, the many and the few

\section{Commutating Sides of Expertise Versus the Many and the Historical Background}

Several times in the history of philosophy, claims are made about decision-making which does not rely upon the ordinary subject of thinking, i.e., an individual consciousness or mind. Instead, those claims suppose a plural subject which is so to speak a "flagged concept" or a notion with an asterisk in need of profound explication. The first philosophers, who are considering those opportunities, being it latently or in direct form, are Plato and Aristotle. It is the last, who has contributed with a derivative concept, the Wisdom of the Many, ${ }^{1}$ to this whole field or primordial claim: to use one's consciousness, and mind, as the medium to find or articulate one's opinion among several or many others. According to this standard, there might be theoretical situations and the rule is law-like and not reducible, where a lot or a larger amount of non-erudite or even not succinctly informed people find a better solution to a problem than a couple of experts being overruled or outweighed respectively. Thus, it is also an issue concerning the theoretical set-like relationships between the many and the few if one will the "flagship" or the very foundation of polarity against the modern exclusively extensional understanding of quantification (Lloydt 1966). In consequence, under this same presupposition, one must also anticipate the contrary possibility where several experts do not make up their mind individually, but find a solution as a primordial collective. In this case, the bearer or the very supporter of wisdom does not shift to the other side, so far "the Many," but rests with the sophisticated and informed person, however not isolated or standing for herself instead of forming a substantial collective entity. This last shift, so far, is exhibited in this

Sander Wilkens, PD, Dr., Institut für Philosophie, Technische Universität Berlin, German; main research fields: Philosophy and Theory of Consciousness, Classical and Modern Logic, Theory of Opposition and Polarity, and Political Philosophy. Email: sander.wilkens@arcor.de. 
instance together with the conditions of polarity, whereas the first shift, named the "Wisdom of the Many," has been exploited in the literature.

As a matter of fact, the core of the claim belongs to political philosophy or philosophy of right as the metaphysical tradition has by far privileged the other path: To make the singular substance, the sole being, the one against the whole world and the others outweigh any formation and/or constellation, where this same token has to be considered in a substantial or essential form of interconnection and interrelationship. This is the portal to recollect Aristotle because there might be a classical situation within a constituted nation-state, where the expert or a smaller amount of experts are overruled by several or many uninformed experts, who seem to know it better. This, of course, is not the rule, instead of a crucial possibility so that it must form a substantial challenge for any form of rationalism. In which way ever there might arise a situation where singular or individual expertise, respectively, relying upon succinct judgement and decision-making, is overruled or simply outweighed by a group of people who have gathered, know the issues but are not experts, and find commonly, together or collectively, a solution which is in the long run and/or under peculiar circumstances the best, at least better than those of the expert(s)?

This last phrase, beginning with the "by," requires full explanation. When several people come together in order to make up their mind, they normally do this for themselves in order to utter their opinion, and then convince themselves for one of them. This, however, is not the whole matter. Aristotle thinks of an underlying base, a situation where a focus comes up, which is melting the audience together and this, in a sense, is also the understanding of Hegel. It is worth to comment his contrasting view which for the most part is contained in the foreword of his Philosophy of Right, because he denounces it and calls it a sample of shallowness. The vehicle is a lecture by his pre-incumbent at the Heidelberg University, Jacob Friedrich Fries, who has pronounced the following: "When a nation is ruled by a common spirit, then from below, out of the people, will come life sufficient for the discharge of all public business. Living associations, united indissolubly by the holy bond of friendship, will devote themselves to every side of national service, and every means for educating the people” (Hegel 2001, 14). ${ }^{2}$

This sacred "bond of friendship" is akin to the old philia of Aristotle. In both cases, it is grasped without proper opposition - as if contrary relationship was not available for founding the affiliation of a polis or political community (hence the philia or "bond of friendship" is conceived of beyond the antonymy, hence near to absurdity from the contrary side to contradiction insofar the neglect of any opposition of both kinds is impossible for the human mind). In any case, it makes the members of a city state belong together or real and fully equipped citizens. Fries exaggerates the fact insofar he takes for granted that the modern state could revive this "bond" and even make it the normal foundation of coincident political and social life. Even more, the wisdom seems to have become the normal situation instead of a peculiar case, the anti-regular even if law-like one, where the assembly or the many are on the right side against the few experts—as if there were only one situation, the opposition aborted, and wisdom or non-wisdom (even upper or lower, rich or poor, and good or bad, the rough difference taken for granted) melt into the same "bond of friendship." Hegel, quite understandable, denounced it from scratch, taking it for mere feeling (Gefühl) or founding the ethical world on the subjective contingency of meaning and arbitrariness in order to devaluate the "several thousand-year-long work of reason and mind by means of a simple home remedy, the sentiment or 'Gefühl'.” Revealing the issue's full-scaled opposition, one should not forget that also Hegel was well aware of the human "Band" (as it is called in German) or bond (in a somewhat metaphorical sense, nowadays the social tie or "lien social" in 
French). ${ }^{3}$ In an essay of his early times, he reviewed the proposal for constitution of the Kingdom of Württemberg, ${ }^{4}$ where one can find the conclusion that, among other things, "the proposal for direct suffrage in representation is a deficiency because it treats citizens like unintegrated atomic units rather than as members of a political community.” Hence, he knows very well that membership to a political state and constitution is in need of some essential relationship—or affiliation—which fills each gap or interval, and not the same, from member of member.

\section{From the "Atomic" to the "Molecular" Unit and the Eventual Melting Point}

The "unintegrated atomic unit" against the "member of a political community" demonstrates that there must be both a condition and a faculty of the human consciousness, and its mind alike, to behave in both directions, even if they should not be confused. Hegel asserts (correctly) the alternative as real, so that the human mind must have the opportunity to form a primordial community instead of being forced to exclusively make up his thoughts for himself and express them as the sole being, the atomic unit. The molecular counterpart, however, is the very philosophical problem because by reason of abstraction and reflecting on the individual faculties - in the traditional or modern manner-one cannot claim and conclude, which essential properties are responsible for founding this molecular being, provided that the atomic unit over the last centuries has become self-understanding or commonsense. To concentrate on the terms, the atom, as a philosophical term since Plato and Democrit, means the non-partial, the non-divisible (scilicet, as a logical extremity). Then the molecular, on the other side, would mean the being part-of, or the divisible, and this so far makes good sense in order to be consistent with essential membership, according to Hegel or others, because membership is understood as a segment imparted to every item or element sharing it. Not to mention, that the famous individual should consequentially be understood as a conceptual pole and not the overarching, peremptorily substantial norm, as soon as the focus of this membership is also understood as constitutive of a polar essence: The supplementary counterpart, i.e., the individual, in this case is shifting to represent a pole and not the classical substance.

Even if the molecular faculty of consciousness can be derived from Hegel's understanding of constitutive social membership, and this is challenging enough according to the different eventual and/or possible forms, his standpoint is not equivalent with the analyzed situation so far. As cited, he tends to see the collective faculty through a crucial bias. Therefore, it is not possible that it should be simply identical with what otherwise has to be conceived of as the "organic conception of society" or the "increasing social interdependence that indicated the social, rather than the atomically individual, nature of human beings... achieving community and actualizing freedom are based on recognizing this common mutual interdependence" (Westphal 1993). ${ }^{5}$ Insofar one does not go through his explications of the "Weltgeist," the "Volksgeist," or common spirit as the "allgemeiner Geist” ( $\mathrm{PhR} \S \S 263 \mathrm{Z}$ and esp. 264), he concludes-or simply presupposes-that the Friesian phenomenon could only derive from emotional devotion. Nevertheless, as such it must be focal or the manifestation of a crucible. When people feel, according to Hegel, the "holy chain of friendship," they must be molten together. Each one devoting himself to peculiar ideas, they arouse together a special feeling of common power. This, in turn, has become the well-known political issue of fascistic or "fascicular" behavior (where fascicular corresponds to the commitment of several elements, political minds, to one common intersection, in particular their ruler). What is more interesting at this point is both the question: (i) how the molecular faculty depends from the eventual melting point, and in particular; (ii) why this faculty should not possess an 
intelligible and intellectual counterpart that does not include any exaggerated commitment, any emotional threshold or drive alike. Hegel, to resolve the matters, as an idealist is not able to acknowledge that the melting point or polar faculty is integral to the human mind, where the melting point is a distinct collective representation, not necessarily emotional, and the faculty the natural condition of the human mind responsible for this performance, which, within a crowd, requires also the corresponding explanation of a boiling event (or mental ebullition): The analysis is getting into conflict with his proper understanding of the dialectical method.

Because the subject is intrinsically a social being who needs association with others in order to institutionalize the universal maxims of morality, maxims that cover all people, it is only in the realm of "ethical life" that the universal and the subjective will come into a unity through the objectification of the will in the institutions of the family, civil society, and the state.

This is the overall lexicographical conclusion of his philosophy, ${ }^{6}$ so that the requirement of the systematic relationship between the polar faculty and the eventual melting point will have to reside first with the ancestor of non-idealism, i.e., Aristotle. He, with his politeia—which is also responsible for introducing the "Wisdom of the Many" still to explain a little bit more in detail—is also the theoretician of political philosophy who claims that right at the beginning of the human condition this social being, who needs association with others, is constituted like a political animal (zoon politikon) and must strive for and live within a herd or flock. Thus, the crucible or the polar faculty is entering the scenery once more. And the "social being who needs association with others” will prove at least his ability to join also one's ideas and mind within a common or shared consciousness.

This seems a rather fashioned and unproblematic formulation. If one considers that it implies the molecular design, and in particular the arrangement with a divisible polar at the center of the nation-state, following the herd or crucible responsible for the condition of the human as a political being, the image converts. Beginning with terminology, the normal situation in reception is such that Hegel's terminology, the concepts, the thoughts as their composition, and finally the historical matters fit quite well together. After acknowledgment that the method concerns his dialectical approach, one can follow his analytical procedure in order to find the terms matching the concepts, thoughts, and historical background. Nevertheless, the need for polar understanding which—-to remind—is underlying his argument against the shallowness of the Fries' social bond of common friendship alters the situation. Presupposing that this bond is succinctly subject to a melting focus or polar consciousness within a crowd or an assembly of several people-Fries, of course, is entitling the whole people or nation - a number of core methodological concepts of Hegel's philosophy become ambiguous: the "Entzweiung" or diremption, the reversion in the peripetian sense (German Umschlagen), the "Zusammensein" or coincidence as the necessary disjunction of a polar opposition, finally the middle point (Mittelpunkt) and the "spheres" as instances of focality. These are only the prevailing instances, but once acknowledged, the terms are entering the field of ambiguity. Then the logical necessity of utmost fame in the after-classical period, i.e., modernity — to rescue the mind from ambiguity or to guide it into the realms of disambiguation-would lead to the point, where polarity is seen in first instance, at least to understand it non-mingled with the dialectical approach. Hegel, therefore, seems not to have the last word in the overall issue.

These characteristics are also true of Aristotle, insofar he does not introduce the term polar or even focus, but is very well aware of the difference of a polar opposition against any other one, in particular the normal contradiction. $^{7}$ To refer to the terminological plan, he is very well using the term "herd" or "flock" in order to 
describe the human faculty and/or condition; so that the polar constituent-as the primary condition—is required because the herd or flock should, in any case, represent a natural melting pot, and its pole(s) are the leading animals or focal substantials, respectively (perhaps even a hierarchical ladder). On the other part, one has to state that his interpretation is rather elusive of this fact. He still does not introduce the entire terminology and its internal interconnections, which, conceded, would have required some new chapter of philosophy and side-guided clear and distinct against naturally confused thinking, in addition, to see the melting point within the brain (consciousness and its perceptions), and outside, within behavior and social gathering. Nevertheless, one has to reconsider Aristotle's statement about the source of a nation-state concerning political "gregarism" or gregariousness, how it is called today, and why this belongs to the essentials of political constitution.

\section{From Gregarious Association to Synthesis and Proper Fusion}

In order to follow this plan from Aristotle-and further to Fichte establishing a centered or concentrated plural subject which, finally, is also capable of proper expertise-a restatement of Aristotle's gregarism as the foundation of a nation-state should begin. The translation runs as follows:

[1] When several villages are united in a single complete community, large enough to be nearly or quite self-sufficing, the state comes into existence, originating in the bare needs of life and continuing in existence for the sake of a good life. And therefore, if the earlier forms of society are natural, so is the state, for it is the end of them, and the nature of a thing is its end. For what each thing is when fully developed, we call its nature, whether we are speaking of a man, a horse, or a family.

According to this explanation, the state is natural as the natural consequence of liaison among humans, their subsequent settlement on shared properties so that afterwards several villages are capable to unite in a single community. Regularly, the reflection about this unification should be considered as the most important issue. Of course, by reason or conceptual summary, one can unite plenty of entities into a common unit, however how it works by itself-as the state's quasi entelechy pursuant to Aristotle-requires complete explanation. It is even not enough to conclude from overarching and inter-crossing needs and desires because this presupposition could end in simple aggregation. Eventually, the members of a community contract or convene to provide each other with goods, services, resources and alike, do not really form a common, single, and complete unity, as Aristotle formulates.

Under this presupposition, gregariousness is the key explanation of Aristotle in order to make comprehensible that the nature category of state and the natural condition of humans correspond as mutual constituents or the preconditional. He states:

[2] Now, that man is more of a political animal than bees or any other gregarious animals is evident. Nature, as we often say, makes nothing in vain, and man is the only animal whom he has endowed with the gift of speech. And whereas mere voice is but an indication of pleasure or pain, and is therefore found in other animals (for their nature attains to the perception of pleasure and pain and the intimation of them to one another, and no further), the power of speech is intended to set forth the expedient and inexpedient, and therefore likewise the just and the unjust. And it is a characteristic of man that he alone has any sense of good and evil, of just and unjust, and the like, and the association of living beings who have this sense makes a family and a state.

No question, this is both a very famous and-as it will appear-simple thought and explanation. The political animal Aristotle’s claims are equivalent with gregarious animals. Gregarious animals follow: (i) their 
instinct, and (ii) normally also a leading member among their flock, sometimes a group of animals too. ${ }^{8}$ This leading property among the group bound together as a unit will then regularly demonstrate the polar constitution: The flock is a herd unless the instinct is coincident with. Further, as the flock or herd is unified by polarity, it is able to fragmentize, even largely, by the peripheral counter-force and, once more, to polarize with one or several opponents as properly absorbed focal instances. Empirical evidence is provided by situations of singular opponents of the same race or not, i.e., a (i) challenger of the leading figure, where the flock behaves as a bound periphery, (ii) the predator which makes the whole flock behave as a single unit. The renamed baroque pond with the cluttered fishes, therefore, is not necessarily to be counted one by one into the "unum per aggregatum," instead of providing the focal instance substantializing the flock in a very peculiar manner, i.e., intra- and inter-polarization. Besides the theory of substance, this whole matter belongs to political theory, also to modern social theory, ${ }^{9}$ and should for the moment be left behind. However, when Aristotle is claiming for the zoon politicon or political animal, he should also imply the polar constitution as the normal condition of a nation-state. To define the issue, this does not mean that the first condition of political constitution - which is the main subject of Aristotle's investigation - is surrounding the focus of political ideas and their different impact of attractive force but that the very condition of a nation-state or the political formation is polar, i.e., grounded in a situation of enabling several centers of power-making and partial or complete exercise. To map the situation on a scalable force belonging to a population which might create its state, the utmost force and likelihood are given in that case, where it behaves like a melting pot, gathers around focal instances and makes the periphery up to the limit sensible and real, where the given stranger or non-citizen-against a possible ostracized or prisoner-is forming the excluded counterpart. So it is not aggregation or agglomeration, not a simple or interrelated chain of common events and experiences, and also not a strip of fertile lands and/or the building of a city — not in the last instance - but a real melting which, by reason of a shared flexible nod of affiliation or "network," must happen within the substantial orientation of consciousness and is capturing the citizens (phratrie) into one common entity. On these grounds, it is then immediately understood and shared as their proper national group, which, and in particular which, has to evolve further into their single statehood. This situation (and analysis) is both at least compatible with the division of powers and, on the other side, an issue of equivalent complication concerning the appearance of a nation-state, now further undeletable evidence over the centuries: Since his own times, the polis has been bound to a fragmentized or diffused picture of societal behavior of power entitlement according to the layers of the so-called rich against the poor-the "mainframe"-and the depolarizing settlement of political matters by means of law-making and court-judging. Eventually, under this presupposition, one has also to account for a balance-crippling multi-polar-faceting as is the contemporary situation. To understand a state, one has to understand polarity and its implications.

Now the second conclusion from the citation above is more than only in an indirect manner related to the doctrine of the "Wisdom of the Many." To recall, Aristotle is founding his assertion about the political nature of humans, hence, their innate inclination to form a common societal flock, upon the human speech. This is, concerning rationality, rather astonishing but he is convinced and takes it both for granted and evident as well that the humans' speech and communication are reflecting the gregarious condition, even at the utmost level among the entire graduation of the animals. Of course, then language or this property of expressing one's ideas and signifying material or intangible things in the common sphere of experience must include the identical polar condition: It is the overall effect of interpolarization within an established community (i.e., a state), enabling, forcing, and training any affiliate member to intrapolarize the matters attached, sign systems, 
symbolization, localization, and designating means. One step further, now investigating the core situation of political decision-making, where several people have to decide upon a matter and have the option to leave it for decision by the experts or to find the solution by themselves, this condition cannot be excluded. Thus when-according to the doctrine of the "Wisdom of the Many"-often in political experience the many which are not experts but meet each other, make up their minds and find a solution by sharing a common view which, in turn, overruns the opinion of the expert(s), then the condition of this whole process cannot exclude the polar ingredient. If the many share a view which represents their natural pole—as the "many" versus the "few" form natural counterparts of a polar relationship (according to Aristotle) - then the Wisdom might shift from one pole to the other side and interchange the basic relationship (a sort of commutation). The other question is immediately conclusive as is the hypothesis above-if also the "few" instantiated by the experts may express their pole by shifting an instance of the "many" to themselves and founding a collective or instantaneously shared consciousness, instead of making their decision solely as the individual person, countable and substantiable on their own.

Already Jeremy Waldron recently has drawn the connection between the language argument and the doctrine. At once, he devaluates the so-called "summation argument," i.e., one has to count up the several instances of a shared view in order to account for its power of resolution. In the core of the argument, he insists, must reside another explanation. Of course, he should be right when introducing and reflecting the polar condition and its main argument following which the political as a gregarious animal has to communicate by means of its speech or natural language. Instead, he resides with the powers of dialectics and synthesis. "I think," he says, "Aristotle has in mind something more synthetic or even dialectical. His view is that deliberation among the many is a way of bringing each citizen's ethical (and, of course, political) views and insights—such as they are-bear on the views and insights of each of the others, so that they cast light on each other" (Waldron 1995). ${ }^{10}$

Presupposing this condition, the casting of light on each other's opinion in a situation of non-singular, i.e., plural decision-making, and the social crucible or the polar function of language which, according to Aristotle, decides the very association of several people in order to be enabled to form a nation-state, then this "bearing on each other's view" or the "casting of light" entails two properties, the melting and the fascicle (as natural expression of polar consciousness, interconnected to a common node, which only under peculiar political pressure evolves into fascism; this is not a necessity and would confuse condition and outcome on the extremities). As representations melt, well-known from Cartesian-Leibnitian philosophy and modern logical interpretation of language, the view or opinions of several people who are engaged to find a common solution for a problem or matters concerning the ruling of a nation-state should include this same property. So, on the whole, another solution is entering the core of the theoretical configuration. The molecular condition which, according to Hegel, is responsible for his being an accountable societal member is coincident with a certain level of melting represented by each member of a nation-state against any foreigner or somebody excluded, ostracized etc. Further, as the crucible, at once containing the will and the representation ideas of (political) representation via their expression in non-congruent opinions, is unavoidably involved, the melting should allow graduation up to a common melting, even boiling point: the threshold of ebullition, where cases tend to fall from one to the other side, hence the extremity among the possibilities of a peripety within a political association. This scaling, even scalar, of the melting point is therefore profoundly affiliated to finding a majority, and the rationalization of a majority cannot be excluded from the conditions of polarity, be it within 
the human mind or within societal and political constitution. When within divisive debate the melting property where different opinions meet, is presupposed, then they should not only cast a light upon each other but tend to fuse more or less heavily and retain its threshold at a certain level. Depending on the supporting and interconnected consciousness, it will become immediately or eventually the common or decided matter, i.e., the will of a "majority" (substantiated plenitude) still affiliated to a minority as the representative of the counter-pole. Eventually the wisdom (the decision encompassing the matters and their necessary situation) is not necessarily bound to be coupled with the majority, or conversely, and this is conditional for the need to show how it might shift and commutate. In any case, the forming of a decided matter within a faction cannot mean that representations stay with their aggregate or naturally confused origin because the melting point or stretch, where several opinions find their common intersection, can be fairly, even highly distinct.

This explanation can be inserted into the elaborate interpretation of Waldron. In several instances, where he is trying to rationalize the internal grounds of the doctrine of the Many, overruling the (singular) expert or person of utmost standing, a further step consistently accommodates his dialectical or synthesis approach within the polar interpretation. To provide another insight, Waldron is contrasting the doctrine with J.S. Mill's suggestions about the synthesis of diverse ideas in On Liberty. In this place, Mill comes up with the idea of a sole person doing the synthesis for all. Mill suggests that in practical life, a regular mind is not capacious and skilled enough in order to fulfill the reconciliation and to be sufficiently impartial. So the expert once more is entering the scenery in order to overrule the multiple lower graded minds. If one will, it marks the standard how "wisdom" should behave against the rationale, which otherwise is condensed in the doctrine of the many, where it must shift to the other side and make the latent polarity or polar foundation manifest. Instead, Waldron concludes that any absence of a "master synthesizer" may actually be an advantage. In the end, the view that emerges will end up being by someone (one hopes by all, or by most, including the case where the multitude is found on secondary line by following the expert's assessment). "There may nevertheless be," he continues, "something to the idea of a consensus emerging in open discussion rather than being actively engineered" (Waldron 1995). ${ }^{11}$ This emerging of a consensus has become a large subject in the philosophy of the last decades concerning Habermas. To concentrate on the conditional plans given here, this "master synthesizer" is: (i) congruent with the possibility of a normal leader of the herd, its personal focus or eventually the faction leader, unless this condition is naturally provided, otherwise someone else from the plenum who has been inspired. Now if (ii) this leader does not come up, the condition of the crucible does not evade or implode instead of remaining virulent. So that-instead of being engineered - the issue of the clear and distinct melting point is the crucial aim of divisive opinions, where they could find their common rest within the overall rating, faceting, and implementation of views. This presupposition even remains stable against the possibilities of habituation and simple or mere communality—in order to reselect the possible cases-because habituation should bear a peculiar gravity or orientation against the coincident disorientation, falling back on the latent polar relation, and communality might represent the common balance or simple indifference between the polar extremities where they seem to find their rest.

This, however, appertains to the foundations of the relation and the final reflection therefore belongs to logic. "The individual member of the multitude is required by the logic of his (and their) enfranchisement," i.e., the individual should be able to find certain detraction from himself, "but to use it in a way that interacts deliberately with others, so that the final vote in the assembly reflects a synthesis which is something more than a mere aggregation of its constituent parts" (Waldron 1995). ${ }^{12}$ As mentioned, Waldron presupposes that the 
logic should be dialectical, i.e., (i) opponents do not fall apart in a strict complementary manner (mutually exclusive like classical contradiction or ortho-negation). If that is correct, (ii) the dialectical approach is, at least, ambiguous as it is congruent with the polar condition. The very logical property of a polar opposition distinctive of its form of negation is that the opponents do not fall absolutely apart (accordingly, one has to read an equivalence in this place), but imply their negative fusion (i.e., the "fuser" from one side of the extremity, correlative to a factor) within the constitutive of a focal—the criterion is that even at the utmost, overridden extremity the opponent is contained, against in particular contradiction which makes the parts fall separately apart by simple conversion (to read formally: $\mathrm{w} \vee \mathrm{f} \mid \mathrm{f} \vee \mathrm{w}$, where limit coincidence, the polar condition, is excluded or complementarity required, available for terms-attributes, or p, q). So considering the enfranchisement, the assembly's deliberate interaction, it is passing over to polarity in the constitutive sense. This does not mean that the opinions should necessarily polarize-which is a matter of appearance-but that the assembly, by itself, has the property of a crucible, a producer of a succinct spread of focuses amidst the overall shared consciousness; in order to essentially melt the "constituent parts" or to create that special point of merging, where the aggregation becomes a "synthesis" according to Waldron or a more or less distinct polar fusion according to this explanation.

\section{Fichte and the Plurality of Experts}

The final section is devoted to Fichte which has a peculiar reason. It concerns the question from the first section, thus the question of alternative commutation, when several relations are coupled and at least one, if not a plurality, are polar ones or antonomies (i.e., a class of opposition behaving like an antonomy with implied special continuum not like the antinomy which, according to classical understanding, presupposes the serial equivalent opposition in every possible instance). Therefore, in first instance, it is not the transcendental claim which should introduce the final section, even if polarity cannot be excluded from the transcendental condition to the extent that it has to explain the very condition of the human mind. Likewise, it is not the cell of idealism in order to shift to the molecular stem of Hegel and provide it with the overarching source or insight against Fichte's constraint upon the "I" and "Not-I." Recalling Hegel's suggestion and if it is true that the center of assembly entails the opposition of an atomic unit against the molecular member- the terminology and the underlying polar opposition have been spelled out-then the question is, why the melting faculty responsible for any distinct intersection between several of those members should not possess both an intelligible and intellectual counterpart. To provide evidence, even a textual proof, one has to alter the constellation. Instead, in modern terms, taking the normative perspective of the observer, one has to assume the normative perspective of the participant. The alternation will also exchange the involved persons' signification. And instead of the third person, it is the first one which will become the primary subject, and the question is if the process of the "Wisdom of the Many" can be reconstructed or observed from so to speak inside. Now, fortunately, this whole examination can be shortened. Two citations from the 1804 lecture of the Science of Knowledge of Fichte show the following: (i) Fichte during this whole lecture having 28 crucial and elaborate parts abolishes the standpoint of the "I." Even if sometimes he is passing over without proper reflection, he never substantially resumes the transcendental issue of endowing the "I" with knowledge and capabilities responsible for the foundations of transcendental philosophy. Instead, it is constantly the plural form, the "We." This does not mean to simply address the audience in the lecture hall but really to circumscribe, introduce and bestow the first person plural subject with the centre of immediate transcendental reflection, i.e., with the real nod and bond of understanding 
responsible for collecting and connecting any of the arguments (not of cultural or political content). Concerning the doctrine of the "Wisdom of the Many," therefore, there should be, at once, an assembly too, where those "Many" are the experts, signifying themselves by their unifying "We," which, in turn, must present a unified or solitary consciousness residing with a collective. Hence, the normal allocation can be crossed and/or commutated; insofar the centre of final decision-making alters together with the coupled second polar relationship of more or less utmost significance.

According to the steady assumption that the polar opposition is primordially involved, this should not make wonder. The decision-making is eventually free to commutate from the molecular unit to the atomic one, thereby providing it with plural or collective substance, the normal-even normative- "fascicle" (the term as explained above; it appertains to set theory to explain its formation, however it not simply the crowd, people, even not the ambiguous group or set itself as soon as polarity plus focality is coincident with the constitutive principle of a set; "molecular" versus "atomic" cannot, of course, be interpreted on simple complementary grounds, the classical habit). The human consciousness, therefore, must provide the capability to be concentrated —and not only concatenated—commonly in a shared instance, even an instance that is chaining argument after argument, and this does not depend on simple psychological attention or the concentration of the mind's faculties. Instead, as mentioned, this concentration must represent the focus of common consciousness which does bestow — at least tries to bestow — everyone attending and participating with: immediately the same thoughts. Two citations should follow to provide the evidence. The first one-of nearly a hundred citable—reads the following way:

[1] As of this last word, I will be regarded as a silent and vanished one, and you will have to take in my place. Anything which by now will be thought in this assembly should only be thought and be true to the extent that you yourself have thought it and understood as being true" (Fichte 1985). ${ }^{13}$

This citation functions as the introductory presupposition. Hereby the speaker provides to substantially take his standpoint, i.e., his personal focus of thinking to be shared immediately and non-intersected. In the following second quotation, he endows his audience with the real subject of common, interfered thinking and conclusion-finding, implemented from the utmost level.

[2] At some point, the concept, if it is generated, must generate by itself and really through itself, without any addition and any need of a "We." Because this "We," as is very well understandable for us, everywhere presupposes a preceding knowledge, and it cannot achieve an immediate knowledge at all. Thus, we are not able to generate the conditions and they immediately generated themselves by themselves: The reason definitely independent from arbitrariness and freedom had to generate them (the conditions) from and through itself (Fichte 1985). ${ }^{14}$

The level of reason is very well dependent from both the knowledge and the situation of the consciousness. However, it is strictly conceived of as the immediate plural subject signified by "We." Even if this "We" does not have immediate possession of knowledge about any of the steps that transcendental argument wants to achieve, it must pass the escalation of receiving utmost "Wissen" by means of this transcendental subject addressed under the obliging form of "We." To recall the whole investigation-thereby passing the limits of Fichte's philosophy — the very focus of immediate stepwise knowledge he relies upon should: (i) provide prominent evidence for the possibility to center the "Wisdom of the Many" with the experts, i.e., make them emanate as a common plurality (instead of numerical individuals one by one). In other words, if singularity versus plurality signifies a polar relationship, it may shift—commutate- the prevailing focus from one to the 
other side (and should be able by reason of the lawful conditions of polarity). Hence, (ii) the situation has altered insofar the fundamental opposition many (-) few must imply the focus of consciousness as a reliable instance of plural thinking, decision-making, and conclusion. In last instance or (iii), the doctrine of the "Wisdom of the Many" entails a crucial amount of necessary rethinking of the classical conception of consciousness, on political, societal, and theoretical grounds.

\section{Notes}

1. Waldron, J. 1995. "The Wisdom of the Multitude: Some Reflections on Book 3, Chapter 11 of Aristotle’s Politics.” Political Theory 23.4, 563-586.

2. Acc. to: Hegel, G. W. F. 2001. Philosophy of Right, translated by S. W. Dyde. Batoche: Ontario, 14.

3. Two examples cited without comment: (i) "Such a law may have the authority of God, of the State, and of centuries, in which it united men and gave substance to their acts and destiny. It may thus include the convictions of an untold number of individuals. And yet to it, I oppose the authority of my private conviction—a conviction which has no other footing than authority. This, to all appearance, stupendous presumption is ignored by the principle which makes subjective conviction to be the rule" (Hegel, PhR, §140 e, trans., Dyde, 126).

(ii) "This absolute self-complacency may in some cases pass beyond a solitary worship of itself, and frame some kind of community, the bond and essence of which would be the mutual asseveration of conscientiousness, good intentions, and reciprocal delight in purity” (Hegel, PhR, §140 f, trans., Dyde, 128).

4. Hegel, G. W. F., 1817. “Proceedings of the Estates Assembly in the Kingdom of Württemberg, 1815-1816,” published in the Heidelbergische Jahrbücher.

5. Westphal, K., 1993. “The Basic Context and Structure of Hegel’s Philosophy of Right.” In: Beiser, Frederick C. (ed.). The Cambridge Companion to Hegel. Cambridge: CUP, 236, 244.

6. Duquette, David A.. “Hegel’s Social and Political Thought.” In: The Internet Encyclopedia of Philosophy (rev. 2005).

7. Lloyd, G.E.R. (1966). Polarity and Analogy. Two Types of Argumentation in Early Greek Thought. Cambridge: CUP.

8. An aspect several commentators in the scholarly field do neglect.

9. Concerning fragmentarization, see Nassehi, A. (2009). Der soziologische Diskurs der Moderne. Frankfurt: Suhrkamp, ch. 5.

10. Waldron 1995, 569.

11. Waldron 1995, 571.

12. Waldron 1995, 575.

13. Fichte, J. G., 1985. Die Wissenschaftslehre (Vortrag 1804). In: Gesamtausgabe der Bayrischen Akademie der Wissenschaften, Nachgelassene Schriften, Band 8, Stuttgart-Bad Cannstadt: Frommann/Holzboog.

14. Fichte 1985, GA 8, 63.

\section{Works Cited}

Hegel, Georg Wilhelm Friedrich. Philosophy of Right. Trans., S. W. Dyde. Batoche: Ontario, 2001.

Lloyd, Geoffrey Ernest Richard. Polarity and Analogy. Two Types of Argumentation in Early Greek Thought. Cambridge: CUP, 1966.

Waldron, Jeremy. “The Wisdom of the Multitude: Some Reflections on Book 3, Chapter 11 of Aristotle's Politics.” Political Theory 23. 4 (1995), 563-86.

Westphal, Kenneth. "The Basic Context and Structure of Hegel’s Philosophy of Right.” In: Beiser, Frederick C. (ed.). The Cambridge Companion to Hegel. Cambridge: CUP, 1993. 